\title{
SIR, IT IS MY OPINION THAT...
}

The BDJ Upfront section includes editorials, letters, news, book reviews and interviews. Please direct your correspondence to the News Editor, Kate Quinlan at the BDJ, The Macmillan Building, 4 Crinan Street, London, N1 9XW or by email to BDJNews@nature.com

Press releases or articles may be edited, and should include a colour photograph if possible.

\author{
Stephen Hancocks OBE \\ Editor-in-Chief
}

A 11 parts of the $B D J$ are subject to various controls, regulations, restrictions, rubric and conventions. Much of the journal is subject to peer review, a process by which the content is read and commented upon by at least two knowledgeable or expert referees who provide reports as to the paper or article's accuracy, quality, value and relevance to the $B D J$ and the literature. That is quite as it should be especially for a long standing and well respected journal. However, there are two other sections where this need either does not apply at all or is required in a different context; letters to the editor and opinion.

We receive hundreds of letters a year and the decision whether or not to publish them is always tinged with subjectivity. Primarily the letter or email expresses the correspondent's opinion or his or her thoughts and experience on matters of fact, or on opinion previously expressed within or outwith the journal. As such they cannot be subject to peer review. One can agree or disagree with an opinion but one cannot peer review it. Some letters we could not publish at all as, written with sincerity and certainly with passion, they are libellous or potentially so. Others make points previously made or revisit old subject matter without adding a new sense or further developing an argument or narrative.

What I have attempted to do is to make the $B D J$ a safe and progressive place in which to nourish debate. I earnestly believe that as a mature profession we should be able to hold vigorous exchanges of views in order to broaden our understanding, share our experiences and ultimately improve our patient care.

\section{'Denial of expression of oppos- ing views gets us nowhere...'} articles that may well not be 'right'; by which I mean that they may not accord with mainstream thinking. Publishing such content is not done for the sake of controversy itself but in order firstly to inform readers that such views are held by others in their profession and secondly to allow readers to also express either their support for, or objection to, such personally held views. Additionally, it helps arm each of us with opposing points of view. With over one hundred thousand unique visitors to the journal's website each month, many of whom access the letters pages, I would argue that there is indeed probably no better peer-review process currently in

place in international dentistry. There are matters on which almost universal agreement abounds and the postbag reflects this. The recent General Dental Council's annual retention fee hike was a good example. Conversely, anything remotely connected to orthodontics seems to provoke almost as many responses and diverse opinions as there are clinicians practising the discipline - and more. Whether or not any, none or all of these stances are 'true' I have no idea but that is not my job; my job is to provide the forum in which they can be raised with clarity and sense whilst being juxtaposed with other content that does provide evidence and as much truth as we can currently muster or attribute. Subject always to further advances in our knowledge and experience.

Some readers feel that this approach actually devalues the journal by making it apparently open to the rantings of correspondents who as a consequence demean the reputation of the profession. But what better way to quash such nonsense (if indeed it is) than by having one or more responses that explain (to everyone else) why it is nonsense? The argument is that publication of these views in a scientific journal gives them validation, But the 'scientific' does not encompass letters and opinions. Indeed many subsequent responses then emphasise the need for scientific validation before the ideas can be considered mainstream. But no evidence can be produced for or against until an idea is aired. It is also argued that patients and members of the public may be misled into giving credibility to an idea by being told that it is being discussed in the $B D J$. I disagree. In fact in such cases I would argue that it is even more important that the rest of the profession is made aware of 'unusual' views and the subsequent debates so as to inform the answers that they can give their patients.

I do not always manage to achieve an equitable balance but I believe that I get it about right most of the time. If I don't you soon tell me; and that is also as it should be. However, I believe that there are notable subject areas in which we can be proud that our columns have made a positive difference to the profession and to our patients, informing, contributing, and adding weight and value to arguments and discussions. I see many reasons why that should continue.

DOI: $10.1038 /$ sj.bdj.2015.392 